\title{
Wet conductor surfaces and the onset of corona discharges
}

DOI:

10.1109/CEIDP.2015.7352076

Link to publication record in Manchester Research Explorer

\section{Citation for published version (APA):}

Li, Q., \& Rowland, S. M. (2015). Wet conductor surfaces and the onset of corona discharges. In host publication (pp. 245-248). IEEE. https://doi.org/10.1109/CEIDP.2015.7352076

\section{Published in:}

host publication

\section{Citing this paper}

Please note that where the full-text provided on Manchester Research Explorer is the Author Accepted Manuscript or Proof version this may differ from the final Published version. If citing, it is advised that you check and use the publisher's definitive version.

\section{General rights}

Copyright and moral rights for the publications made accessible in the Research Explorer are retained by the authors and/or other copyright owners and it is a condition of accessing publications that users recognise and abide by the legal requirements associated with these rights.

\section{Takedown policy}

If you believe that this document breaches copyright please refer to the University of Manchester's Takedown Procedures [http://man.ac.uk/04Y6Bo] or contact uml.scholarlycommunications@manchester.ac.uk providing relevant details, so we can investigate your claim.

\section{OPEN ACCESS}


This is the accepted manuscript, which has been accepted by IEEE for publication (C) 2015 . Personal use of this material is permitted. Permission from IEEE must be obtained for all other uses, in any current or future media, including reprinting/republishing this material for advertising or promotional purposes, creating new collective works, for resale or redistribution to servers or lists, or reuse of any copyrighted component of this work in other works. The full reference is:

\section{'Wet conductor surfaces and the onset of corona discharges' \\ Qi Li and S. M. Rowland}

IEEE Conference on Electrical Insulation and Dielectric Phenomena,

pp. 245-248, 2015

DOI: $\underline{10.1109 / C E I D P .2015 .7352076}$ 


\title{
Wet Conductor Surfaces and the Onset of Corona Discharges
}

\author{
Qi Li and S M Rowland \\ School of Electrical and Electronic Engineering \\ The University of Manchester \\ Manchester, United Kingdom \\ s.rowland@manchester.ac.uk
}

\begin{abstract}
Corona discharges initiated from water droplets on the surface of overhead line conductors are considered. The size of droplets on conductors with a range of surface hydrophobicity is evaluated. A range of droplet sizes are then selected on which to perform experimental studies of their dynamic behaviour under electric fields. It is found that the droplet varies its shape at twice the power frequency through a semi-spherical, flattened (tortilla), and conical cycle. Further experiments performed with various sized droplets identified that the phase relationship between the vibration and applied voltage is dependent on the size of the droplet. High speed UV imaging is used to capture vibration and UV emission simultaneously. Corona discharge initiates from the tip of a $3 \mu \mathrm{L}$ droplet when it is in a conical shape while it is initiated from the edge of a $5 \mu \mathrm{L}$ droplet when its shape is flattened. It is concluded that corona inception is affected by the droplet size range which can form on the surface of a conductor. This is mainly dominated by the surface hydrophobicity of conductors, and will impact the acoustic emission from conductors in service. Significant differences may result between $50 \mathrm{~Hz}$ and $60 \mathrm{~Hz}$ power frequency systems.
\end{abstract}

Keywords-water droplet; corona discharge; high voltage conductor; overhead line; hydrophobicity; contact angle; droplet vibration; multiphase flow; acoustic, noise

\section{INTRODUCTION}

The onset of corona is a key factor in designing overhead line systems. This is controlled by the first stages of breakdown of the insulating air around the conductor surface. This breakdown process is very reproducible for a controlled environment and geometry. However in an overhead line neither the environment nor geometry are well controlled.

Existing commercial design packages use algorithms developed many years ago, at a time when it was not necessary to work close to operating margins. Moreover conductor designs considered were of a round-strand type, whereas many new 'compact' designs have trapezoidal strand shapes and modified surfaces. The effect of the stranding shape has been considered in recent publications [1-2]. Whilst idealised models of conductors are readily easily understood, the reality is that corona onset is caused by surface defects and pollution. This paper considers the way in which water droplets change the surface field on a conductor and hence change its high voltage characteristics.
The formation of water droplets on the surface of an overhead line conductor is affected by a few factors. Factors such as weather conditions can vary by region and season, and provide a wide size range of rain droplets on the surface of a conductor. Other factors include the designed surface electric field of the overhead line conductor (commonly referred to by the equivalent field strength on a cylindrical conductor), the surface finish (stranding shape and roughness) of the conductor, the hydrophobicity of the conductors and the power frequency of the transmission line (either $50 \mathrm{~Hz}$ or $60 \mathrm{~Hz}$ ). Understanding the impact these factors have on the onset of corona discharge, and thus the emissions such as audible noise [3], is the main motivation of this paper.

Of particular interest is the dynamic movement, mainly vibration, of the collection of droplets. A previous publication has shown experimentally using high speed photography and synchronized electrical measurements that there is a phase delay between the applied voltage and the droplet vibration [4]. The present contribution focuses on this vibration behaviour of various sized droplets. It is identified that this phase delay is a function of droplet size. As a result, naturally occurring large droplets have very different behaviour from smaller droplets: the corona initiation and intensity is as different. The implications for the field management around conductors is considered.

\section{LITERATURE REVIEW}

Early work on corona discharge from droplet can be found from 1960s when Taylor published his experiment [5] in which a soap bubble was used to explain the electro hydrodynamic phenomena within a high electric field. He then developed a theoretical analysis to explain the relationship between droplet stability and the tip angle [6]. This model is well known as 'Taylor's cone' which is essential to understand the physical mechanisms of droplet separation when the electric field exceeds a critical value. Most of the experiments related to 'Taylor's cone' are driven by DC voltage supplies in which the droplet is relatively immobile. The shape of the liquid interface is determined by Maxwell's tensor and surface tension, and is static before it reaches instability.

A more common case within the overhead power line application is when the supplied voltage is alternating at the power frequency typically 50 or $60 \mathrm{~Hz}$, and the droplets' shape 
is subjected to a dynamic movement. This periodical movement modifies the distribution of surface charge and thus the Maxwell's tensor. This adds a complication to the stability of the liquid interface. Teich and Weber [7] carried out early studies on vibrating droplet on the surface of overhead line conductors. Their experiment was designed by to examine the oscillation of pendant water droplets under a $100 \mathrm{kV}$ AC supply voltage. However the work is only focused on pendent droplets on a very hydrophilic conductor. Dynamic behaviour was also evaluated on the water stream from the bottom of conductors [7-8]. As a result of the development of composite insulators, considerably more work has been published on water droplet behaviour on insulation surfaces [10-19].

\section{EXPERIMENTAL}

\section{A. Overall Set-up}

The experimental set up is an advanced design based on the previous work [4]. The overall set-up is shown in Figure 1. Sphere and plane electrodes are used to maintain the axialrotational symmetry of the electric field. A high speed optical system is utilized to capture both the droplet vibration and UV emission from corona discharge.

\section{B. Design of High Voltage Electrodes and Circuit}

The earth plate has smooth round edges to prevent undesired corona discharges. The critical design parameters which determine the distribution of the electric field surrounding the sphere are (with typical values):

- the diameter of the aluminium sphere (42 $\mathrm{mm})$

- the distance between sphere and electrode $(75 \mathrm{~mm})$

- the diameter of the plane electrode $(200 \mathrm{~mm})$

An FEA model has been developed to determine the electric field distribution for various sphere diameters, gap distances and dimensions of earth plate. Values used are compared to the values expected on conductors in service [1]. These parameters are optimized so that the electric field distribution is closest to the operational level of overhead line conductors. Electrodes are designed to give $16.5 \mathrm{kV} / \mathrm{cm}$ rms field strength on the surface of the sphere without a droplet. It is also noted in this case of a sphere electrode the field is divergent in two planes not one as for a conductor/cylinder. Electrical diagram for the testing circuit is shown in Figure 2.

An $80 \mathrm{kV}$ transformer is employed as the HV supply. The $125 \mathrm{k} \Omega$ current limiting resistor is present to limit any flashover current. A surge protection device (spark gap) is
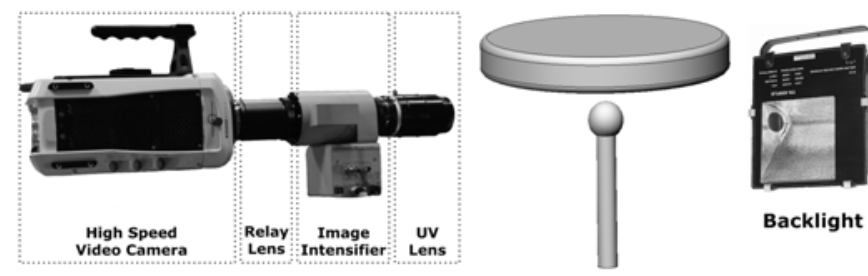

Optical System for High Speed UV

Sphere-to-plane Set up

Fig. 1. Experimental Set-up

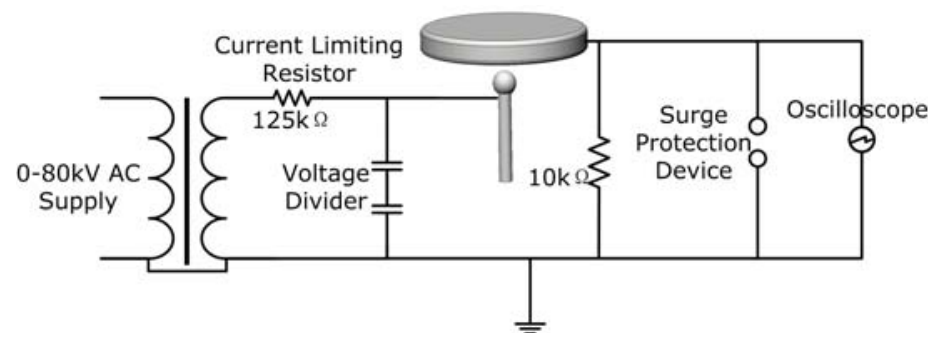

Fig. 2. Circuit diagram for the experiment

introduced to protect the secondary measurement circuit. A voltage divider is used to measure the supplied voltage value on the HV electrode.

\section{Combined Optical System for High Speed UV Detection}

UV light from corona discharge has a wavelength ranging from $190 \mathrm{~nm}$ to $400 \mathrm{~nm}$. It is not visible directly by human eye and is be filtered out by standard optical lenses. To be able to capture UV emission from corona discharge, a specific UV lens (Nikon $105 \mathrm{~mm}$ F4.5 UV Lens) is employed. Because the light intensity of UV emission from corona discharge is much lower than visible light, and the high speed camera further reduces this light intensity, it is not possible to capture corona profile directly through the high speed video camera. A high speed gated image intensifier is brought into the system to magnify the light intensity by 1000 times. This gives sufficient light intensity to feed into the high speed camera. This electronic magnification increases noise level present on the image, so captured images are processed by a specifically designed MATLAB code to filter the noise.

The high speed camera and intensifier are synchronized to capture images with an interval time of $40 \mu \mathrm{s}$. The frame rate of the combined optical system is 25,000 frame/second. The voltage waveform is measured on a voltage divider at a rate of 10 measurements per image (250,000 per second) and is synchronized with captured images flicker free.

\section{RESULTS AND DISCUSSION}

\section{A. Water droplets' formation on the surface of the conductor}

Droplet size distributions on the surface of conductors is determined by the hydrophobicity of the surface. To evaluate the effect of hydrophobicity on the droplet size, three short sections of conductor sample are subjected to the same wetting condition until they are fully wetted. A photograph of this is shown in Figure 3.

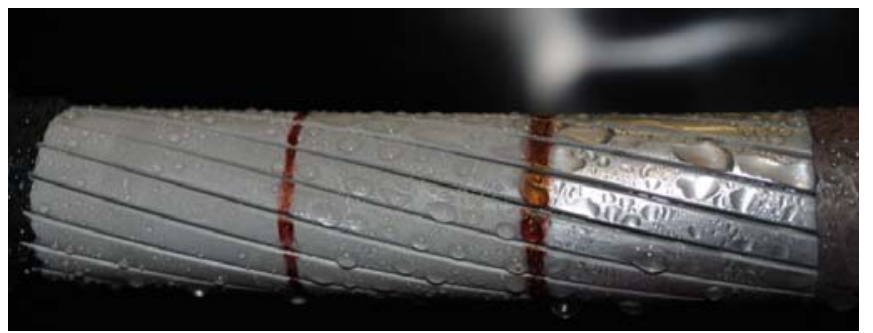

Fig. 3. Formation of water droplets on the surface of different hydrophobicities 


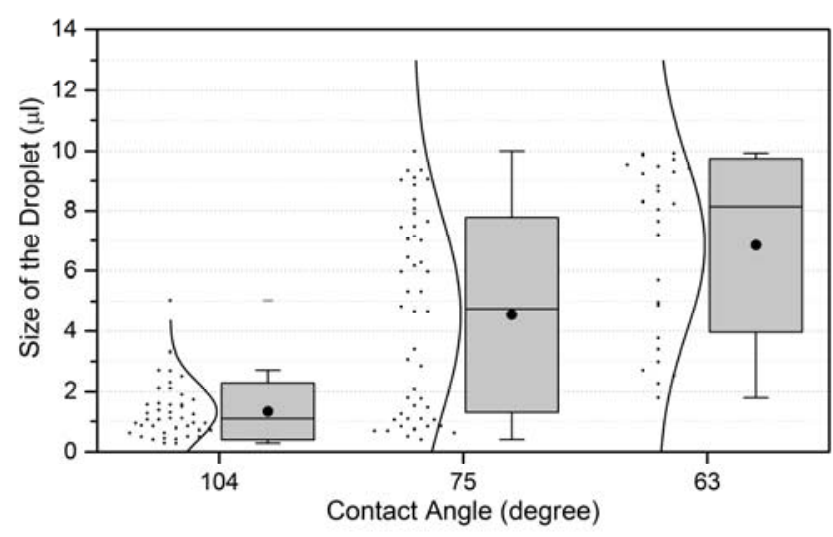

Fig. 4. Statistical plot for droplet size distribution in microlitres

An imaging technique, based on Young-Laplace equation is utilized to estimate the size of the droplets presented on the surface. The distribution is plotted in a statistical diagram in Figure 4. It is observed that

- the average droplet size is larger for a more hydrophilic surface $(1 \mu \mathrm{l}, 5 \mu \mathrm{l}, 7 \mu \mathrm{l})$

- the standard deviations for surfaces with different hydrophobicity are: $0.92 \mu 1,3.21 \mu \mathrm{l}$ and $2.84 \mu \mathrm{l}$ for contact angle of 104, 75 and 63 degree respectively

\section{B. Vibration chracteristics of water droplet}

Previous work on droplet vibration has shown that when subject to AC electric field, the shape of the droplet alters through each half power cycle between three states of outline shapes: semi-spherical, flattened (tortilla), and conical [4]. For the droplet presented in Figure 5, the maximum field occurs when the droplet is in a flattened profile rather than when it is 'pointed'. However this is not true for all the droplets.

Study of the vibration characteristics of various sized droplets, shows that the phase relationship between applied voltage and the shape is highly dependent on the size/volume of the droplet. This is because the natural frequency of the droplet vibration decreases when the volume of the droplet increases [19]. Vibration theory explains that the phase delay between excitation and response is mainly determined by the difference of excitation frequency and natural frequency of any vibration system. As a result, the voltage waveform shown in

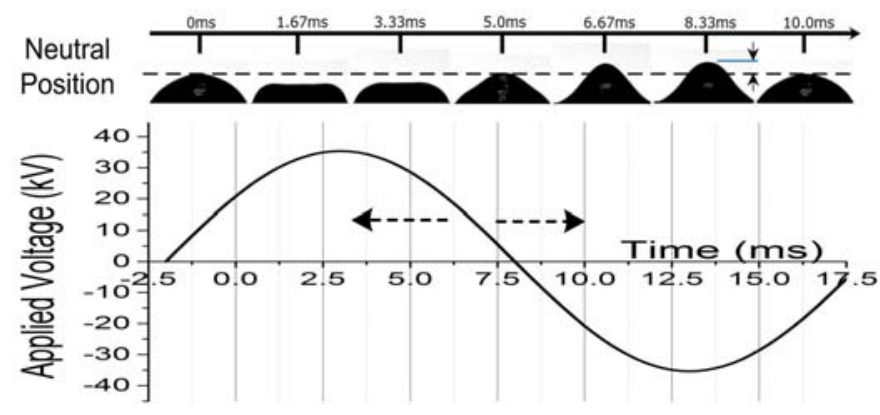

Fig. 5. A typical profile of droplet vibrating under AC electric field. The shape of droplet is shown with the point-on-wave, showing the phase relationship between peak voltage and maximum droplet height.
Figure 5 can be shifted towards left or right (i.e. the phase difference is increased or decreased) with respect to the droplet shape variation, depending on the size of the droplet.

\section{Corona onset on two droplets with different volumes}

High speed imaging system as introduced previously is utilized to simultaneously capture both droplet shape and UV emission from a vibrating droplet. The captured image is shown in Figure 6. The black area indicates the spherical electrode and the shape of the droplet, the light white area indicates UV emissions captured by high speed imaging system, and the gray area is the background. It is observed from Figure 6 that:

- corona discharge is initiated from a $3 \mu$ droplet when the shape is conical.

- corona discharge is initiated from a $5 \mu$ droplet when the shape is flattened.

- on a $3 \mu 1$ droplet the corona discharge initiated from the tip of the conical shape, which is a unique location in the system.

- on a $5 \mu \mathrm{l}$ droplet the corona discharge initiated from the edge around the flattened shape (tortilla), which presents a circular line or locus of potential initiation locations.

The voltage signal, magnitude of vibration and the light intensity captured by the optical system are plotted against time for $3 \mu \mathrm{l}$ and $5 \mu \mathrm{l}$ droplets in Figure 7 and Figure 8 respectively. For convenience of comparison, all three variables are plotted in per unit base. The voltage reference used is a ratio between the instantaneous value and the maximum peak voltage. The UV intensity is detected through imaging process and is computed from integration of light intensity within the related area. For the purpose of comparison, this value is thus unified to be within 0-1 range (where ' 1 ' indicates the highest light intensity observed). The vibration magnitude is defined as the largest distance between droplet surface and the electrode on which it sits. It is also unified to be varied between 0 and 1 .

The distinction between these two plots is the phase relationship between voltage and the vibration. The magnitude of vibration for $3 \mu \mathrm{l}$ droplet is around $15^{\circ}$ lagging the applied voltage, while in the $5 \mu \mathrm{l}$ droplet case, this angle increased to approximately $90^{\circ}$. This indicates that the mass change from 3 $\mu \mathrm{l}$ to $5 \mu \mathrm{l}$ modified the droplet's natural frequency of vibration, and as a result the phase angle between excitation and response is increased. The corona inception voltage for $3 \mu \mathrm{l}$ and $5 \mu \mathrm{l}$ droplets are $28.8 \mathrm{kV}$ and $32.2 \mathrm{kV}$ respectively. The increased inception voltage level suggests that the shape of droplet has an effect in increasing electric field when it is conical and

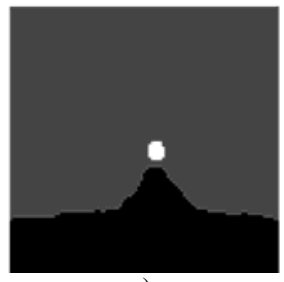

a)

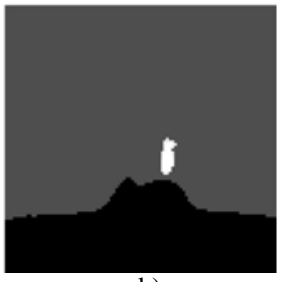

b)

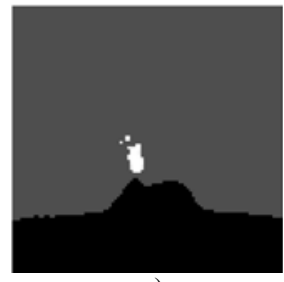

c)
Fig. 6. A typical corona discharge initiated from vibrating droplet $(3 \mu \mathrm{L}$ droplet: a, $5 \mu \mathrm{L}$ droplet: $\mathrm{b}$ and c). 
reducing field when it is flattened shape. These experiment were performed at $50 \mathrm{~Hz}$. It is to be expected that $60 \mathrm{~Hz}$ experiments would give similar results but the impact of water droplet size would be changed due to the change in natural resonant frequency.

\section{CONCLUSION}

The vibration of water droplets on $50 \mathrm{~Hz} \mathrm{AC} \mathrm{high} \mathrm{voltage}$ metallic surfaces has been studied experimentally and through FEA. In particular, corona onset voltages have been studied. It has been verified by experiment that the phase relationship between the shape function and applied voltage is strongly dependent on the size of a droplet. As a result of the phase difference, a $3 \mu \mathrm{l}$ droplet initiates corona discharge when the droplet is in a conical shape while a $5 \mu l$ droplet generates corona discharge on a flattened shape during the AC cycle. This finding identifies a cause of a key difference in the corona behaviour on the surface of wet conductors: the range of droplet sizes determining vibration, corona and as a result acoustic emissions. The resonant nature of the phenomenon implies there may be significant differences between $50 \mathrm{~Hz}$ and $60 \mathrm{~Hz}$ power systems.

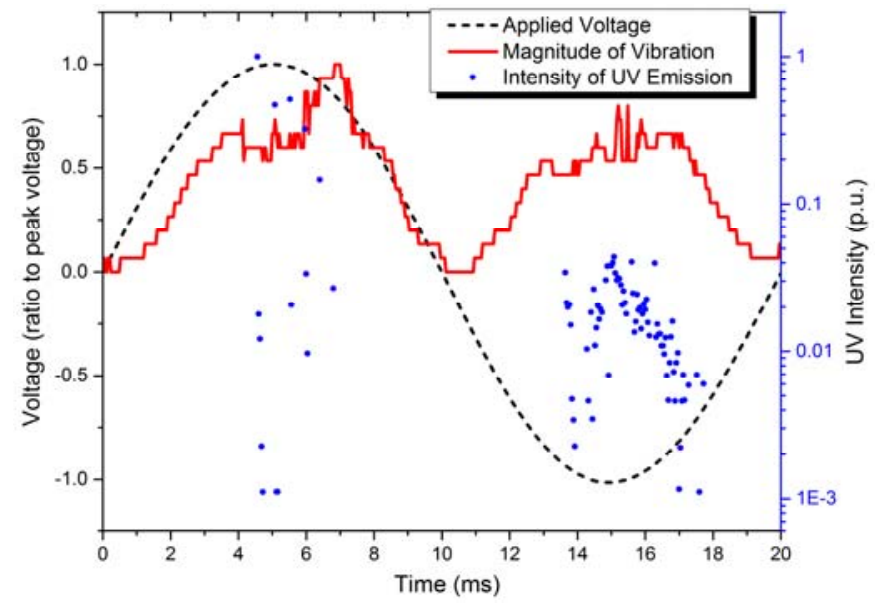

Fig. 7. High speed UV results for a $3 \mu \mathrm{L}$ water droplet

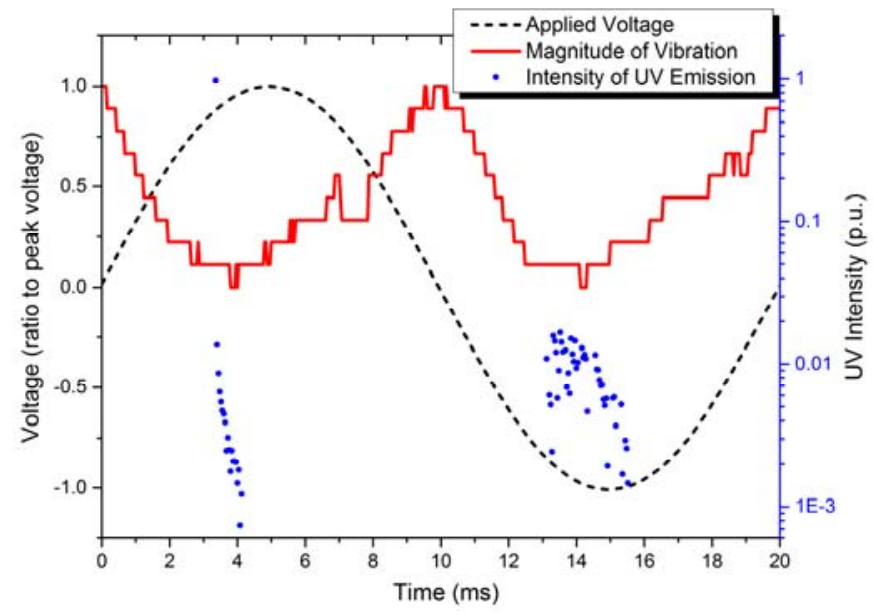

Fig. 8. High speed UV results for a $5 \mu \mathrm{L}$ water droplet

\section{ACKNOWLEDGMENT}

The Authors are grateful to National Grid UK for their support for this work.

\section{REFERENCES}

[1] Q. Li, S. M. Rowland, and R. Shuttleworth, "Calculating the Surface Potential Gradient of Overhead Line Conductors," Power Delivery, IEEE Transactions on, vol. 30, no. 1. pp. 43-52, 2015.

[2] Q. Li, R. Shuttleworth, G. Zhang, S. M. Rowland, and R. S. Morris, "On calculating surface potential gradient of overhead line conductors" International Symposium on Electrical Insulation, pp. 540-544, 2012.

[3] Q. Li, R. Shuttleworth, G. Zhang, I. Dupere, and S. M. Rowland, "Acoustic noise evaluation for overhead line conductors," in Electrical Insulation Conference (EIC), 2013 IEEE, 2013, pp. 119-123.

[4] Q. Li, R. Shuttleworth, I. Dupere, G. Zhang, S. M. Rowland, and R. S. Morris, "FEA modelling of a water droplet vibrating in an electric field," International Symposium on Electrical Insulation, pp. 449-453, 2012.

[5] G. Taylor, "Disintegration of water drops in an electric field," Proc. R. Soc. London, Ser. A (Mathematical Phys. Sci., vol. 280, no. 1382, pp. 383-397, 1964.

[6] G. Taylor, "Electrically Driven Jets," Proc. R. Soc. London. A. Math. Phys. Sci., vol. 313, no. 1515, pp. 453-475, Dec. 1969.

[7] T. H. Teich and H.-J. Weber, "Origin and abatement of tonal emission from high voltage transmission lines," e\&i Elektrotechnik und Informationstechnik, vol. 119, no. 1, pp. 22-27, 2002.

[8] Y. Yuan, X. Jiang, S. M. Rowland, A. Xiao, Q. Li, and S. Wang, "Calculations of breakdown voltage of rod-plane air gaps in the presence of water streams," IEEE Trans. Dielectr. Electr. Insul., vol. 22, no. 3, pp. 1577-1587, Jun. 2015.

[9] Y. Yuan, X. Jiang, S. Rowland, X. Cheng, and Q. Li, "Effect of water streams on the AC breakdown performance of short rod-plane air gaps," IEEE Trans. Dielectr. Electr. Insul., vol. 21, pp. 1747-1756, 2014.

[10] O. Fujii, K. Honsali, Y. Mizuno, and K. Naito, "Vibration of a water droplet on a polymeric insulating material subjected to AC voltage stress," IEEE Trans. Dielectr. Electr. Insul., vol. 17, no. 2, pp. 566-571, Apr. 2010.

[11] Y. Higashiyama, T. Yamada, and T. Sugimoto, "Vibration of water droplet located on a hydrophobic sheet under the tangential AC field," Industry Applications Conference, 1999. Thirty-Fourth IAS Annual Meeting. Conference Record of the 1999 IEEE, vol. 3. pp. 1825-1830 vol.3, 1999.

[12] Y. Higashiyama, T. Yamada, and T. Sugimoto, "Effect of resonance of a water droplet located on a hydrophobic sheet on AC flashover," Industry Applications Conference, 2002. 37th IAS Annual Meeting. Conference Record of the, vol. 3. pp. 2198-2203 vol.3, 2002.

[13] Y. Higashiyama, S. Yanase, and T. Sugimoto, "Behavior of water droplets located on a hydrophobic insulating plate under DC field," $33^{\text {rd }}$ Industry Applications Conference,. pp. 1808-1813 vol.3, 1998.

[14] Y. Higashiyama, T. Takada, and T. Sugimoto, "Resonant vibration and flashover phenomena of a water droplet located on a hydrophobic sheet under ac field," J. Electrostat., vol. 63, pp. 883-889, 2005.

[15] K. Katada, Y. Takada, M. Takano, T. Nakanishi, Y. Hayashi, and R. Matsuoka, "Corona discharge characteristics of water droplets on hydrophobic polymer insulator surface," in Proceedings of the IEEE International Conference on Properties and Applications of Dielectric Materials, 2000, vol. 2, pp. 781-784.

[16] S. Keim, D. Koenig, and V. Hinrichsen, "Experimental investigations on electrohydrodynamic phenomena at single droplets on insulating surfaces," in Conference on Electrical Insulation and Dielectric Phenomena (CEIDP), Annual Report, 2003, pp. 133-136.

[17] S. M. Rowland and F. C. Lin, "Stability of alternating current discharges between water drops on insulation surfaces," J. Phys. D. Appl. Phys., vol. 39, no. 14, pp. 3067-3076, Jul. 2006.

[18] R. Sarathi and G. Nagesh, "UHF technique for identification of discharges initiated by liquid droplet in epoxy nanocomposite insulation material under ac voltages," J. Phys. D. Appl. Phys., vol. 41, no. 15, p. 155407, Aug. 2008.

[19] T. Yamada, T. Sugimoto, Y. Higashiyama, M. Takeishi, and T. Aoki, "Resonance phenomena of a single water droplet located on a hydrophobic sheet under AC electric field," Industry Applications, IEEE Transactions on, vol. 39, no. 1. pp. 59-65, 2003. 